\title{
Commentary: Incubation and Intuition in Creative Problem Solving
}

\author{
Yuan Yuan ${ }^{1,2}$ and Wangbing Shen ${ }^{3 *}$ \\ ${ }^{1}$ School of Psychology and Lab of Cognitive Neuroscience, Nanjing Normal University, Nanjing, China, ${ }^{2}$ School of \\ Rehabilitation Science, Nanjing Normal University of Special Education, Nanjing, China, ${ }^{3}$ Institute of Applied Psychology and \\ School of Public Administration, Hohai University, Nanjing, China
}

Keywords: incubation, creative insight, dual process theories, mental impasse, intuition

\section{A commentary on}

Incubation and Intuition in Creative Problem Solving

by Gilhooly K. J. (2016). Front. Psychol. 7:1076. doi: 10.3389/fpsyg.2016.01076

There is a peculiar psychological phenomenon referred to as incubation; it is regarded as one of Wallas 's (1926) four stages of creativity and is defined as a departure from an ongoing unsolved problem that can lead to, or make more likely, the sudden or insightful solution of a difficult problem. Although the existence of incubation effects has long been recognized, the mechanism underlying incubation remains unclear.

Gilhooly (2016) concluded that the Unconscious Work hypothesis (UWH) provided a better

OPEN ACCESS

Edited by:

Dermot Lynott,

Lancaster University, UK

Reviewed by:

Aidan Feeney,

Queen's University Belfast,

Northern Ireland

${ }^{*}$ Correspondence:

Wangbing Shen

won.being.shin@gmail.com;

wbshenhhu@126.com

Specialty section:

This article was submitted to

Cognitive Science,

a section of the journal

Frontiers in Psychology

Received: 31 July 2016 Accepted: 02 November 2016 Published: 16 November 2016

Citation:

Yuan Y and Shen W (2016)

Commentary: Incubation and Intuition

in Creative Problem Solving.

Front. Psychol. 7:1807.

doi: 10.3389/fpsyg.2016.01807 explanation of incubation than the Intermittent Conscious Work (ICW) and Beneficial Forgetting (BF) hypotheses, and noted that incubation was an interesting finding that warranted further investigation. We agree with Gilhooly (2016) that the UWH provides an important account of incubation effect in divergent thinking, but here we consider a complementary perspective that deals primarily with the dual-process theory (DPT) of incubation during creative thinking, particularly convergent thinking or insight problem solving (insightful incubation). DPT has been applied to a range of cognitive processes such as judgment/decision-making (Greene, 2007), reasoning (Evans, 2008), and creativity (Lin and Lien, 2013; Weisberg, 2015).

As Gilhooly (2016) noted, the kind of convergent thinking required to solve insight tasks is just as important to creative thinking as divergent thinking. Divergent thinking processes are illdefined, relatively unconstrained, and generate multiple solutions whereas convergent thinking relies on speed, accuracy, logic, and the capacity to recognize the familiar quickly in order to identify the single solution to a well-defined problem (Cropley, 2006; Chermahini and Hommel, 2012). To solve divergent thinking tasks such as the alternative uses task the solver only needs to switch freely between perspectives and select one subdominant characteristic of the common object (Chrysikou and Thompson-Schill, 2011; Gilhooly, 2016); he/she can easily generate infrequent uses of this object. In contrast, solving an insight problem with a defined solution requires one to understand the logic underlying the solution, to restructure one's initial representation of the problem, relax certain constraints, and overcome a set-related impasse through failure-driven learning.

There is mounting evidence that solving most convergent thinking tasks, in particular, insight problems, depends on conscious cognitive control, including working memory, inhibition, updating, and switching (Koppel and Storm, 2014; Gilhooly et al., 2015; Lv, 2015). It is often assumed that the process of overcoming an impasse, or shifting cognitive setcommonly regarded as the defining feature of insight-happens during insightful incubation (Christensen and Schunn, 2005; Zhan et al., 2015). The process of set-shifting or overcoming an impasse is a controlled, internally driven shift in strategy which has been linked to 
activation of the medial prefrontal region (Schuck et al., 2015) and to an error-related negative potential in the same region (Bartholow et al., 2005). The controlled inhibition of irrelevant associations or inappropriate thought patterns is required to overcome an impasse or shift cognitive set during insightful incubation (Koppel and Storm, 2014; Lv, 2015). Replacing inappropriate thoughts with appropriate ideas, which is considered essential to the process of overcoming an impasse, relies on memory updating (Jones, 2003). Gilhooly (2016, p.7) stated that "unconscious work is parallel, inexact and divergent while conscious thought is serial, exact, and convergent."

The UWH cannot accommodate findings on insightful incubation effects (Zhong et al., 2008) because it describes incubation solely in terms of unconscious processes. A DPTbased model of incubation in terms of unconscious and conscious processing does not suffer from this problem. Our DPT model of incubation accepts, like the UWH, that unconscious processes are critical to incubation, but posits that there are two systems of thinking: system 1, which is characterized by rapid, implicit, parallel and unconscious processes and system 2, which relies on slow, explicit, sequential, conscious processes (Evans, 2008). Also, the DPT believes the conscious process underlying incubation is not intermittent and always goes with unconscious processes during the whole incubation period. Moreover, the DPT of incubation extends the UWH in three critical ways.

Firstly, the DPT proposes that both conscious and the unconscious processes are critical to incubation, whereas the UWH does not assign conscious processes any role in incubation. The UWH cannot explain why filling the incubation period with a light cognitive demand task has more incubation effect than filling it with rest or a demanding task. The DPT explains this by assuming that performing an undemanding task ensures that both unconscious and conscious processes are recruited during incubation, whereas resting makes incubation an entirely conscious process and performing a demanding task makes it entirely unconscious because cognitive resources are depleted by the task (Sio and Ormerod, 2009). Importantly, the DPT can resolve the conflicts between the UWH and other incubation theories/findings like the BF theory or the explicit-implicit interaction model (Hélie and Sun, 2010). Moreover, Zhong et al. (2008) found that unconscious thought can increase solution

\section{REFERENCES}

Bartholow, B. D., Pearson, M. A., Dickter, C. L., Sher, K. J., Fabiani, M., and Gratton, G. (2005). Strategic control and medial frontal negativity: beyond errors and response conflict. Psychophysiology 42, 33-42. doi: 10.1111/j.14698986.2005.00258.x

Chermahini, S. A., and Hommel, B. (2012). Creative mood swings: divergent and convergent thinking affect mood in opposite ways. Psychol. Res. 76, 634-640. doi: 10.1007/s00426-011-0358-Z

Christensen, B. T., and Schunn, C. D. (2005). Spontaneous access and analogical incubation effects. Creat. Res. J. 17, 207-220. doi: 10.1080/10400419.2005.9651480

Chrysikou, E. G., and Thompson-Schill, S. L. (2011). Dissociable brain states linked to common and creative object use. Hum. Brain Mapp. 32, 665-675. doi: 10.1002/hbm.21056 accessibility but may reduce the actual solution quantity when compared with conscious thought; this result is inconsistent with the UWH but is accommodated by the DPT. Sio and Ormerod's (2009) meta-analysis on incubation studies concluded that both unconscious and conscious processes were involved.

Secondly, the DPT can account for both insightful incubation and certain incubation-related phenomena in divergent thinking, such as the superiority of immediate incubation. Gilhooly (2016) argued that the difference between immediate and delayed incubation is that one of the two only involves unconscious processing whereas the other also involves conscious processing (for details, see Gilhooly et al., 2012). Given that initiating a "dual-task" delayed incubation (involving the target task and interpolated task) relative to a "single-task" immediate incubation will cost more cognitive resources, the conscious and unconscious processes could both be involved in immediate incubation but only the unconscious process in delayed incubations due to an additional depletion in cognitive resources for the interpolated task during an immediate incubation.

Finally, the DPT can explain the inverted-U shaped relationship between unconscious thoughts and creative performance (Yang et al., 2012) and the timing of the unconscious thought advantage during the incubation process. Only when the duration deliberation is moderately long, neither too long nor too short, can the unconscious thought offer significant advantages over conscious thought(Yang et al., 2012); over short or long deliberation periods, the creative output of conscious thought surpasses that of unconscious thought.

\section{AUTHOR CONTRIBUTIONS}

WS and YY discussed the study and co-wrote this comment. WS and YY revised this comment according to the reviewers' comments. All authors have read and approved the final manuscript.

\section{ACKNOWLEDGMENTS}

This work was supported by the National Natural Science Foundation of China (31500870) and the Fundamental Research Funds for the Central Universities (2014B15314).
Cropley, A. (2006). In praise of convergent thinking. Creat. Res. J. 18, 391-404. doi: $10.1207 /$ s15326934crj1803_13

Evans, J. S. B. (2008). Dual-processing accounts of reasoning, judgment, and social cognition. Annu. Rev. Psychol. 59, 255-278. doi: 10.1146/annurev.psych. 59.103006 .093629

Gilhooly, K. J. (2016). Incubation and intuition in creative problem solving. Front. Psychol. 7:1076. doi: 10.3389/fpsyg.2016. 01076

Gilhooly, K. J., Ball, L. J., and Macchi, L. (2015). Insight and creative thinking processes: routine and special. Think. Reason. 21, 1-4. doi: 10.1080/13546783.2014.966758

Gilhooly, K. J., Georgiou, G. J., Garrison, J., Reston, J. D., and Sirota, M. (2012). Don't wait to incubate: immediate versus delayed incubation in divergent thinking. Mem. Cognit. 40, 966-975. doi: 10.3758/s13421-0120199-z 
Greene, J. D. (2007). Why are VMPFC patients more utilitarian? A dualprocess theory of moral judgment explains. Trends Cog. Sci. 11, 322-323. doi: 10.1016/j.tics.2007.06.004

Hélie, S., and Sun, R. (2010). Incubation, insight, and creative problem solving: a unified theory and a connectionist model. Psychol. Rev. 117, 994-1024. doi: 10.1037/a0019532

Jones, G. (2003). Testing two cognitive theories of insight. J. Expl Psychol: Learn. Mem. Cogn. 29:1017. doi: 10.1037/0278-7393.29.5.1017

Koppel, R. H., and Storm, B. C. (2014). Escaping mental fixation: incubation and inhibition in creative problem solving. Memory 22, 340-348. doi: 10.1080/09658211.2013.789914

Lin, W. L., and Lien, Y. W. (2013). The different role of working memory in openended versus closed-ended creative problem solving: a dual-process theory account. Creat. Res. J. 25, 85-96. doi: 10.1080/10400419.2013.752249

Lv, K. (2015). The involvement of working memory and inhibition functions in the different phases of insight problem solving. Mem. Cognit. 43, 709-722. doi: 10.3758/s13421-014-0498-7

Schuck, N. W., Gaschler, R., Wenke, D., Heinzle, J., Frensch, P. A., Haynes, J. D., et al. (2015). Medial prefrontal cortex predicts internally driven strategy shifts. Neuron 86, 331-340. doi: 10.1016/j.neuron.2015.03.015

Sio, U. N., and Ormerod, T. C. (2009). Does incubation enhance problem solving? A meta-analytic review. Psychol. bull. 135, 94-120. doi: 10.1037/a0014212

Wallas, G. (1926). The Art of Thought. New York, NY: Harcourt Brace Jovanovich.
Weisberg, R. W. (2015). Toward an integrated theory of insight in problem solving. Think. Reason. 21, 5-39. doi: 10.1080/13546783.2014.886625

Yang, H., Chattopadhyay, A., Zhang, K., and Dahl, D. W. (2012). Unconscious creativity: when can unconscious thought outperform conscious thought? J. Consum. Psychol. 22, 573-581. doi: 10.1016/j.jcps.2012. 04.002

Zhan, H. J., Liu, C., and Shen, W. B. (2015). Neural basis of creative thinking during four stages. Adv. Psychol. Sci. 23, 213-224. doi: 10.3724/SP.J.1042.2015. 00213

Zhong, C. B., Dijksterhuis, A., and Galinsky, A. D. (2008). The merits of unconscious thought in creativity. Psychol. Sci. 19, 912-918. doi: 10.1111/j.1467-9280.2008.02176.x

Conflict of Interest Statement: The authors declare that the research was conducted in the absence of any commercial or financial relationships that could be construed as a potential conflict of interest.

Copyright $(2016$ Yuan and Shen. This is an open-access article distributed under the terms of the Creative Commons Attribution License (CC BY). The use, distribution or reproduction in other forums is permitted, provided the original author(s) or licensor are credited and that the original publication in this journal is cited, in accordance with accepted academic practice. No use, distribution or reproduction is permitted which does not comply with these terms. 